\title{
Using law and licences to supply accessible books to visually impaired students at the University of Chester
}

\author{
Lisa Peters, Craig Smith
}

\begin{abstract}
Provision of accessible copies of textbooks to visually impaired students has an important role to play in supporting them in their studies, including at university. Recent legislative and copyright licence developments have allowed libraries to supply textbooks to their students in a form best suited to their needs. Whilst these developments are welcome, actually obtaining accessible textbook for visually impaired university students is neither simple nor straightforward and is often a laborious and time consuming process. The University of Chester has provided accessible books to visually impaired students since 2011 and established an Alternative Formats Team in 2012 to manage this service. This article describes the processes, usage and challenges of this service, as well as providing a brief description of the RNIB resource Load2Learn.
\end{abstract}

\section{Introduction}

In recent years, the University of Chester has seen a rise in the number of visually impaired students. Several of these students attended the same school so the decision to attend the University of Chester may have been based on personal recommendations about the services provided for visually impaired students at the University. The range of visual disability has varied from total blindness to partial sightedness and consequently each student can have very different requirements regarding accessible books. This article explains how the library established a system for supplying accessible books to these students and its success or otherwise in obtaining accessible books from UK and overseas publishers.

\section{Author \\ Lisa Peters is Law Librarian at the University of Chester \\ Email: 1.peters@chester.ac.uk \\ Craig Smith is Assistant Law Librarian at the University of Chester.}




\section{Legal background}

The twenty-first century saw the appearance of several pieces of legislation designed to support people, including students, with disabilities. The Special Education Needs and Disabilities Act (2001) (SENDA) section 26 made it "unlawful for ... an educational institution to discriminate against a disabled student in the student services it provides, or offers to provide" and this required universities to make "reasonable adjustments" to ensure that disabled students receive equal access to services as other students whilst not defining "reasonable".

In 2002, the Copyright, Designs and Patents Act (CDPA) (1988) was amended to include section $31 \mathrm{~B}$ which allowed accessible copies to be made for the personal use of visually impaired persons for whom the original work (book) was not accessible because of their impairment. This section does not apply if the work is commercially available in a form that is accessible to that person. In 2008, section 9 of the higher education licence from the Copyright Licensing Agency (CLA) (2013) permitted universities (the licencee) to make and supply accessible copies in an alternative format to disabled students, subject to the conditions that the licencee had possession of an original copy of the work and that the work was not commercially available in a format accessible to the student. Section $31 \mathrm{~B}$ of the CDPA was limited to visually impaired persons whilst the CLA licence was broader in its scope as it applied to students with other disabilities, such as dyslexia, who required accessible versions. The Equality Act (2010) superseded the Disability Discrimination Act (1995) and SENDA and expanded the definition of "disabled" to include specific learning difficulties such as dyslexia and Asperger's syndrome. Consequently, students who fall under the definition of disabled but are not visually impaired can request that they be supplied with accessible books. This change in copyright law for visually impaired persons was not restricted to the UK alone but was seen in other Western countries, causing Roos $(2007,893)$ to describe the changing laws which now permitted the production of accessible materials for visually impaired persons as "radical departures from the accepted norms of copyright protection". UK law has recently seen further extensions of exceptions to copyright for those with disabilities in the Copyright and Rights in Performances (Disability) Regulations (2014), although the implications of these changes are not discussed in this article.

\section{Similar work}

The importance of being able to supply students with accessible versions of books has been acknowledged many times and as Mates commented:

Failure by libraries to provide full access to information will prevent people from fully participating in the learning process.

(Mates, 2012, 8)

However, libraries have not always been seen as a friendly place for visually impaired students. A recent blog article by McNaught (2015) on the website of the Chartered Institute of Library and Information Professionals described the library as a place that visually impaired students avoided because it contained what they 
perceived to be the "enemy": print books. In addition, much of the literature on how libraries can help visually impaired students has focused on the use of assistive technology or upon e-books. For example, an issue of Library Trends in 2007 (Brazier and Owen, 2007) which was devoted to library services for visually impaired people contained several articles on assistive technologies such as DAISY (Digital Accessible Information System) and website and library catalogue accessibility, rather than discussing accessible books.

The arrival of e-books was thought to provide a solution to the problem of inaccessible books for disabled students. However, e-books have not, as Burton (2015) noted, lived up to their hype and have technological barriers to their use. E-books often contain digital rights management (DRM) which prevents any amendments being made to them. As Robertson (no date) noted, the variety of visual impairment is significant and each visually impaired student requires individual adjustments. Whilst some are content to use 'read aloud' software for the text to be read to them or to use a form of video magnification called CCTV, others require the background colour to be changed or the font altered. DRM software prevents these changes being made. Finally, of course, there are still a significant number of books that are not commercially available in an accessible form, most noticeably ones published before 2000 .

The use of devices such as the Kindle, Nook, Kobo, Sony reader, and Apple's iBook have been recognised in the literature as being beneficial to students who want to enlarge text and change the background colour, although audio access is not always possible. As Junus noted:

E-books present great potential for users with print disabilities to gain access to information that might otherwise be inaccessible to them. If their devices are well designed and outfitted with the appropriate e-text formats, users with visual impairments can read e-books using the assistive technology of their choice ... The e-book publishing boom, however, has created many e-book formats and ereaders that are inaccessible to those with visual disabilities or, in some cases, hearing or learning disabilities.

(Junus, 2012, 22)

It has been difficult to establish what UK universities do to supply accessible textbooks to their visually impaired students outside of providing assistive technology and e-books. Harris and Oppenheim (2003) examined how the Copyright (Visually Impaired Persons) Act (2002) (amending the CDPA) had impacted on the services which libraries in colleges of further education offered to visually impaired students. Whilst the article touched upon accessible books, its main focus was upon assistive technology, library induction and changes to policies.

A number of UK universities clearly state on their website the library services that are available to students with a visual impairment. The Student Disability Service at Oxford Brookes University (2011) transcribes texts into electronic, audio, Braille or large print formats. The University of Strathclyde (no date) has a University Central Scanning Service which scans textbooks under the CDPA 
provisions for students if a suitable e-book version is not available. The library of the University of Liverpool (no date) advertises that it will attempt to obtain an accessible version of core texts from the publisher and it offers an Alternative Format Service whereby it will scan articles and book chapters from items held in stock and supply (as far as possible) an accessible PDF and a Word document free of charge. Bangor University Library and Archives (2011) offers a dedicated contact and states that if students require library resources in an accessible format it will "investigate to see what can be done" depending on the nature of the resources and the publisher.

\section{The procedure at the University of Chester}

The first requests for accessible books came from a visually impaired student in 2011. The student concerned was completely blind and required access to a large number of books for her dissertation and these books were not available as ebooks. Initially Disability Services dealt with obtaining accessible versions for her but this role was passed onto the library as the library had access to module reading lists and was familiar with the legal requirements under the CDPA and the CLA licence. Consequently, for the 2012-13 academic year the library established the Alternative Formats Team (AFT) which was created by the Law Librarian / Legal Compliance Manager, which seemed the most obvious place to locate the AFT in the library due to the complicated legalities involved, and a procedure was drawn up for obtaining accessible books for visually impaired students.

Over the summer, the AFT contacts returning students to request their module choices for the next academic year. Upon receipt of the module choices, the AFT obtains each module's reading list. Whilst concerns have been expressed that focusing on the module reading list unnecessarily limits the books available, it does act as a useful starting point and students are able to request accessible versions of books that are not on the reading list. The AFT knows each visually impaired student's accessibility preferences and if that student is willing to use an e-book, the AFT will check to see if one is available for purchase. If an e-book is available but has not been purchased by the library, the AFT will contact the relevant subject team with a purchase request. If an e-book version is not available, the AFT contacts the publisher to request an accessible version. The AFT uses the Publisher Lookup UK website from JISC TechDis (no date) to obtain contact details for the publisher and then sends an e-mail to the publisher concerned requesting an accessible version and / or completes a form on the publisher's website, such as the McGraw-Hill form (http://stage-new.mcgrawhill.co.uk/forms/visual.html).

The AFT confirms in the e-mail that a print copy of the book is available in the library and also requests a Word version of the book or, if a Word version is not available, permission to convert to Word. The Word request was the result of a particular student who insisted that her accessible books had to be available in Word format and declined to use Adobe PDF as she did not feel comfortable using it. This format has since been adopted as a matter of course to allow students to use their personal preference to choose between the Word or Adobe PDF versions. The AFT is usually required to sign a licence agreement from the 
publisher and make the visually impaired student aware of the terms and conditions that the accessible version is supplied under. Commencing work on obtaining accessible versions in the summer does allow the AFT to ensure that at least some of the books on the reading list are available for the visually impaired student when they return to university.

Conversely, requests from new first year students are not actioned until the student formally registers in induction week. This does cause problems as students have to wait a number of weeks for their accessible books whilst their seeing colleagues can go straight to the library to get the books they need. Whilst this is an unfortunate situation, it is neither legal nor practicable for the AFT to start to obtain accessible versions for a student who may never actually formally register as a University of Chester student.

Upon the AFT receiving an accessible version of the book, it is converted to Word and the two versions (Word and Adobe PDF originally supplied by the publisher) are saved onto a CD. CDs were adopted for their ease of use and availability and the AFT is considering a move to USB pens. The CD is then catalogued onto the library catalogue but the bibliographic record is suppressed and can only be viewed by library staff. Any licence requirements are listed on the $\mathrm{CD}$ for the student to view or for library staff to read to the student. The student is then informed that the $\mathrm{CD}$ is available for them to collect from the library helpdesk and the $\mathrm{CD}$ is added to their library loan account. Accessible books on CD do not count towards the student book allowance of 15 and the loan period is extended to the end of the academic year. Students are restricted to a maximum of $15 \mathrm{CDs}$ at any one time but there is no maximum number of requests that they can make throughout the year.

In order to join the accessible books scheme students are required to sign and agree to a list of terms and conditions which encompasses the publisher requirements. These terms and conditions of the service explain how visually impaired students can request an accessible version of a book that is not on a reading list. The AFT strongly encourages students to give as much notice as possible of their requests as publisher response times do vary and can be particularly lengthy at the start of the academic year. In addition, the response time of the AFT is slower at the start of the academic year due to the number of requests it is dealing with. It is also important to encourage as much notification as possible from academics. Depending on future demands on the service, the AFT may introduce a specific period of notice although so far it has resisted doing this as it does wish to be responsive to student requirements.

\subsection{Obtaining accessible books}

Table 1 shows the number of requests made by the AFT and the response from publishers. The number of visually impaired students has increased from five in 2012-13 to eight in 2014-15 and these students have studied undergraduate and postgraduate degrees in Health and Social Care, English literature, Law, Sociology, Mathematics, Business, Theology, and Psychology. 
In the first year of the service, nearly half of the requests came from one student studying English literature who made numerous requests to support his third year dissertation. Three students have studied English literature and this has allowed accessible versions obtained for one student to be passed onto another the following year, subject to checking that this is permitted under the terms and conditions under which the accessible copy was supplied. When the terms and conditions have not allowed this or have stated that repeat permission must be sought for re-use by a different student, the publisher has been contacted to request permission and this has always been forthcoming.

\begin{tabular}{|l|l|l|l|}
\hline & $2012-2013$ & $2013-2014$ & $2014-2015$ \\
\hline Accessible books supplied by publishers & 78 & 58 & 67 \\
\hline $\begin{array}{c}\text { Publisher unable to supply accessible } \\
\text { book and grants permission to scan }\end{array}$ & 27 & 12 & 9 \\
\hline No response & 10 & 8 & 1 \\
\hline $\begin{array}{l}\text { Publisher will supply accessible version } \\
\text { subject to payment }\end{array}$ & 2 & 2 & 1 \\
\hline Total & $\mathbf{1 1 7}$ & $\mathbf{8 0}$ & $\mathbf{7 8}$ \\
\hline
\end{tabular}

Table 1: Requests made to publishers, 2012-2015.

Ensuring that students have accessible versions of textbooks is a time consuming process. It begins with sourcing reading lists and continues with contacting the publisher, obtaining an accessible version, cataloguing the $\mathrm{CD}$, and concludes with the CD being issued to the visually impaired student. In 2014-2015 the AFT spent the equivalent of six weeks of staff time on sourcing accessible versions for eight students. No one part of the process is particularly time consuming, it is rather the number of stages to work through that makes obtaining accessible versions a particularly lengthy procedure.

\subsection{The response from publishers}

Large UK academic publishers such as SAGE, Oxford University Press, Routledge and Palgrave have dedicated departments for dealing with accessible book requests and operate a quick turnaround, even in the busy October and November months. If an accessible version is not available, usually because the book predates 2000 , permission to scan the book to create an accessible version is given and this scanning is done by the visually impaired student's support worker. Smaller publishers and those who deal with general fiction titles, as opposed to student textbooks, often do not have a dedicated e-mail contact and are therefore contacted through a generic e-mail address. Turnaround from these publishers is slower and occasionally there is no response.

Obtaining US titles is usually more problematic than is the case for UK titles. The websites of US publishers often direct requests for accessible textbooks to websites such as AccessText Network (AccessText, 2014) or Bookshare (Bookshare, 2015) who supply accessible textbooks to visually impaired students 
at US universities and colleges free of charge. Consequently, direct e-mail contact has to be made with the US publisher. US publishers often require confirmation that the student has purchased a copy of the book concerned - a requirement that does not exist in the UK as under section 31B of the CDPA a student only requires "lawful access". Upon explaining UK law, the US publisher is generally content to assist and sends the accessible version or gives permission to scan. However, obtaining accessible books from US publishers is, perhaps surprisingly given the multinational nature of many of them, geared towards dealing with US colleges and universities. It is noticeable that the vast majority of "no response" outcomes shown in the table are from enquiries to US publishers.

Only one publisher has charged a fee to supply an accessible copy and the fee was equal to the purchase price of the physical book. Visually impaired students are given a book allowance as part of their student allowance and are therefore able to use this sum to pay for any accessible versions. In this case, the AFT passes the details onto the student so they can arrange for payment themselves.

If a publisher does not respond to a request for an accessible copy, the AFT can use either the CLA licence or the CDPA to scan the book and convert it to an accessible version, regardless of whether or not the publisher is based in the UK or is a signatory to the CLA licence. The scanning is then done by the visually impaired student's support worker and a summary of the terms and conditions under the CDPA or CLA licence are attached to the CD as usual. The AFT usually waits four weeks for a response from the publisher before authorising the support worker to scan and create an accessible version. This decision by the AFT to allow the publisher four weeks in which to respond is difficult to explain to a student who requires a particular book urgently, especially if the AFT has used the CDPA or CLA licence conditions to allow the support worker to scan a book for them (subject to the four week waiting period) before. The student is aware that the university has the facilities to create an accessible version for them almost immediately and do not understand why they must wait and why a set procedure needs to be followed. This does place a responsibility upon the student to give the AFT as much notice as possible and also for lecturers to notify visually impaired students of their reading requirements well in advance.

\section{Load2Learn}

Load2Learn was founded by RNIB (Royal National Institute of Blind People) and Dyslexia Action in 2011. Membership is free of charge to staff in schools, colleges and universities who are engaged in supporting "print-impaired" learners in the UK (Load2Learn, 2014). The University of Chester is a member of the Load2Learn service which has a number of benefits:

1. The ability to download books in Word, PDF, EPUB, audio, and braille formats from a dedicated database. Images and sheet music are also available. These materials are supplied by the publisher. As of December 2014 over 4,100 titles were available for download (Load2Learn, 2014).

2. Multiple staff, including support workers, disability support staff and librarians, can access Load2Learn under one membership. 
3. Members can request books that are not available on Load2Learn database. Load2Learn then contacts the publisher to arrange for an accessible version to be added to the database and made available to all members. This feature has the potential to eliminate duplicate work across universities and make obtaining accessible textbooks far less cumbersome than contacting publishers individually.

4. Load2Learn is working with several major publishers including SAGE, Oxford University Press, HarperCollins and Palgrave Macmillan to proactively upload accessible versions to their database.

Using Load2Learn in the first instance has in the past yielded some positive results, meaning that the AFT does not have to source the text from the publisher or, more importantly, wait for a publisher to provide the file. If a title is not available for immediate download through Load2Learn, the AFT tends to continue sourcing directly from the publisher as the turnaround time is typically quicker than that experienced with Load2Learn. Load2Learn lists average turnaround times of between one to ten weeks whereas the average AFT turnaround time is two weeks. At present, only $9 \%$ of the titles on Load2Learn are aimed at further and higher education although the service does hope to increase this number significantly. As Load2Learn develops and establishes working relationships with more publishers, it is hoped that, in the not-too-distant future, Load2Learn will have accessible versions of books for most, if not all UK publishers, which can be immediately downloaded into a variety of accessible formats for visually impaired students and other students who have difficulties with the printed book. The recent announcement from Load2Learn that they are working with on a project with Bookshare to provide UK university students with free access to over 150,000 e-books (Load2Learn, 2014) is to be commended and similar international developments should be encouraged.

\section{Conclusion}

The service at the University of Chester was set up very much as an ad hoc response to the needs of one visually impaired student and the desire to provide her with equality of access to textbook resources as was enjoyed by other students. Consequently, the service has evolved on an on demand basis, rather than being set up by university authorities with specific objectives and requirements. The service has been appreciated by students although there have been the inevitable complaints concerning the time taken to obtain an accessible version from publishers. The development of the Load2Learn service is crucial in the development of an effective UK-wide service for visually impaired students, at all levels of the education system. The AFT would strongly support the continued development of the Load2Learn database as one centralised service would eliminate duplicate requests for the same title from multiple universities, thereby saving time and effort for both university and publisher staff. The ability to download books, in the student's preferred accessible format, straight from the Load2Learn database would give visually impaired students a comparable service with other students who merely take the book that they need from the shelf. In addition, publishers should endeavour to make all their books available in e-book 
format for libraries to purchase. It is recommended that all further and higher education libraries strategically consider how they can supply visually impaired students with books that they need to complete their studies successfully, duly considering effective liaison with other relevant support departments such as Student Disability services and with strong support from senior library management.

\section{References}

AccessText (2014) AccessText Network [online]. URL: http://www.accesstext.org [accessed 4.5.15].

Bangor University Library and Archives (2011) Accessibility and disability [online]. URL:

http://www.bangor.ac.uk/library/help/documents/2011/accessibility-disabilityguide.pdf [accessed 4.5.15].

Bookshare (2015) An accessible online library for people with print disabilities [online]. URL: https://www.bookshare.org [accessed 4.5.15].

Brazier, H. and Owen, D. (eds) (2007) Library and Information Services for Visually Impaired People, Library Trends, 55(4).

Burton, S. (2015) The academic e-book landscape: technological problems, CILIP Update, (May), 40-41.

Copyright and Rights in Performances (Disability) Regulations (2014) [online]. URL: http://www.legislation.gov.uk/uksi/2014/1384/contents/made [accessed 21.12.15].

Copyright, Designs and Patents Act (1988) [online]. URL:

http://www.legislation.gov.uk/ukpga/1988/48/section/31B [accessed 30.7.15].

Copyright Licensing Agency (2013) Higher education licence for UUK / GuildHE members [online]. URL: http://he.cla.co.uk/wp-content/uploads/2013/07/CLAHigher-Education-Licence-UUKGHE.pdf [accessed 30.7.15]

Copyright (Visually Impaired Persons) Act (2002) [online]. URL:

http://www.legislation.gov.uk/ukpga/2002/33/contents [accessed 12.12.15].

Disability Discrimination Act (1995) [online]. URL:

http://www.legislation.gov.uk/ukpga/1995/50/contents [accessed 12.12.15].

Equality Act (2010) [online]. URL:

http://www.legislation.gov.uk/ukpga/2010/15/contents [accessed 12.12.15].

Harris, C. and Oppenheim, C. (2003). The provision of library services for visually impaired students in UK further education libraries in response to the Special Educational Needs and Disability Act (SENDA), Journal of Librarianship and Information Science, 35(4), 243-257.

JISC TechDis (n.d.) Publisher Lookup UK [online]. URL: http://www.publisherlookup.org.uk [accessed 4.5.15]. 
Junus, S. G. R. (2012). E-books and e-readers for users with print disabilities. In: Booth, C. (ed.), Making libraries accessible: Adaptive design and assistive technology. Chicago: ALA TechSource. 22-28.

Load2Learn (2014) Load2Learn [online]. URL: https://www.load2learn.org.uk [accessed 4.5.15]

Mates, B. T. (2012) Information power to all patrons. In: Booth, C. (ed.), Making libraries accessible: Adaptive design and assistive technology. Chicago: ALA TechSource. 7-13.

McNaught, A. (2015) Libraries and print impairment - how to go from foe to friend [online]. URL: http://cilip.org.uk/cilip/blog/libraries-print-impairment-howgo-foe-friend [accessed 12.12.15].

Oxford Brookes University (2011) Library services for disabled students [online]. URL: https://www.brookes.ac.uk/library/disabled.html [accessed 4.5.15]

Robertson, L. (n.d.) Access for library users with disabilities [online]. URL: http://www.sconul.ac.uk/sites/default/files/documents/access disabilities 0.pdf [accessed 24.4.15].

Roos, J.W. (2007) Libraries for the blind as accessible content publishers: copyright and related issues, Library Trends, 55(4), 879-916.

Special Educational Needs and Disabilities Act (2001) [online]. URL: http://www.legislation.gov.uk/ukpga/2001/10/pdfs/ukpga_20010010_en.pdf [accessed 30.7.15].

University of Liverpool (n.d.) Accessibility [online]. URL:

http://www.liv.ac.uk/library/using/accessibility.html [accessed 4.5.15].

University of Strathclyde (n.d.) Accessibility and alternative format [online]. URL: http://www.strath.ac.uk/disabilityservice/accessibility/ [accessed 4.5.15].

\section{Acknowledgement}

The authors thank Sue Hultum for her assistance with the research for this article.

\section{Open access and copyright}

Library and Information Research is an open access journal. A freely available copy of this paper may be downloaded from the journal's website: http://www.lirgjournal.org.uk.

Copyright and associated moral rights in works published in Library and Information Research are retained by the author(s) but this paper may be used freely, with proper attribution, in educational and other non-commercial settings. 